\title{
Atividades Agrícolas no Assentamento Iracema (PI) e suas repercussões sobre o Meio Ambiente
}

Agricultural activities in Assentamento Iracema (PI) and its repercussions on the Environment

Activités Agrícoles em le Place Iracema (PI) et leurs répercussions sûr Le Moyen Environment

Actividades Agrícolas em el Sítio Iracema (PI) y sus repercusiónes sobre el Médio Ambiente

\author{
Lúcia de Fátima Correia de Castro* \\ Jaíra Maria Alcobaça Gomes ${ }^{* *}$
}

Recebido em 17/8/2006; revisado e aprovado em 15/12/2006; aceito em 10/2/2007.

\begin{abstract}
Resumo: Os assentamentos rurais no Brasil têm incorporado preocupações com a sustentabilidade econômica e preservação ambiental. Analisam-se as atividades agrícolas e suas repercussões sobre o meio ambiente no Assentamento Iracema, localizado no município de Buriti dos Lopes (PI), através de pesquisa direta realizada em maio de 2004. A sustentabilidade ambiental depende da capacitação das famílias assentadas em técnicas agrícolas, que conservem os recursos naturais, no que diz respeito à não utilização da área de reserva permanente.

Palavras-chave: Reforma agrária; assentamentos rurais; políticas de desenvolvimento e sustentabilidade.
\end{abstract}

Abstract: The agricultural nestings in Brazil have incorporated concerns with the economic sustentabilidade and ambient preservation. The agricultural activities and its repercussions are analyzed on the environment in the Iracema Nesting, located in the city of Buriti of Lopes (PI), through carried through direct research in May of 2004. The ambient sustentabilidade depends on the qualification of the families seated in agricultural techniques, that conserve the natural resources, in that says respect to not the use of the area of permanent reserve.

Key Words: The agrarian reformation; agricultural nestings; politics of development and sustentable.

Résumé: Les places agrícoles em Brésil sonnt em train d'incorporer préoccupations avec la soutenabilité économique et la préservation ambiental. Les activités agrícoles sonnt analysées et leurs répercussions sûr le moyen environment au Place Iracema à la ville de Buriti dos Lopes (PI), a travérs de la recherche directe realisé en mai de 2.004. La soutenabilité ambiental dépend de la capacitation des familles placées em techniques agrícoles que conservent les resources naturaux, sûr qu 'il s'agit à non utilisation de la surface de réserve permanete.

Mots-clé: Reforme Agraire; places agrícoles; politiques de développement et soutenabilité.

Resumen: Los sítios rurales em Brasil tienen incorporado preocupaciónes com la sostenibilidad econômica y preservación ambiental. Analisanse las actividades agrícolas y sus repercusiónes sobre el médio ambiente em el Sítio Iracema, ubicado em la ciudad de Buriti dos Lopes (PI) através de la búsqueda directa realizada em mayo de 2.004. La sostenibilidad ambiental está relacionada com la capacitación de las famílias concentradas em técnicas agrícolas, que conserven los recursos naturales, em lo que dice à respecto à no utilización de la área de reserva permanente.

Palabras clave: Reforma agrária; sítios rurales; políticas de desarrollo y sostenibilidad.

\section{Introdução}

O objeto de análise deste artigo são as atividades agrícolas desenvolvidas no Assentamento Iracema e suas repercussões sobre o meio ambiente. O Assentamento, situado no Município de Buriti dos Lopes, é resultado da ação do Governo Federal segundo as normas do Plano Nacional de Reforma Agrária (PNRA) e do Programa de Reforma Agrária, via desapropriação por interesse social, executado pelo Instituto Nacional de Colonização e Reforma Agrária (INCRA).

A área do Assentamento é indicada em seu Plano de Desenvolvimento Sustentável como possuidora de potencialidades para garantir sustentabilidade econômica e ambiental, assegurando melhores condições de vida para as famílias. Nesta perspectiva, analisar as atividades agrícolas e buscar compreender a situação de trabalho dos assentados e seus efeitos no meio ambiente, como uma estratégia de sobrevivência. A análise apresentada resulta de uma pesquisa direta realizada no Assentamento em maio de 2004.

Discute-se a Política de Assentamento no Brasil como modelo de reforma agrária, origem e classificação dos assentamentos e dificuldades de gestão, potencialidades econômicas, sociais e ambientais do

\footnotetext{
* Mestranda PRODEMA/TROPEN/UFPI (luciafcastro@bol.com.br).

** Professora do Depto. de Economia e PRODEMA/TROPEN/UFPI (jairamag@uol.com.br).
} 
assentamento Iracema, as atividades agrícolas e suas repercussões sobre o meio ambiente.

\section{Reforma agrária: a política de assentamento no Brasil}

A questão da concentração de terra sempre esteve presente na história do Brasil. Desde a colonização, a ocupação e uso do solo forjaram disputas envolvendo diferentes atores sociais por territórios para os mais diferentes fins. Nesta trajetória, a intervenção através de modelos de reforma agrária acompanhou o desenvolvimento do país, encontrando, ainda no Império, sua primeira interferência legal.

Somente em 1946, surge novo aparato legal com o Decreto lei n 9.760 de 1946, que regulamenta a discriminação de terras, procurando reordenar a complexa situação fundiária existente.

No período de 1961-1964, foi aprovado, no governo Castelo Branco, a Lei 4.504, de 30 de novembro de 1964, conhecida como Estatuto da Terra: um conjunto de medidas cujo objetivo era definir políticas agrícolas e de reforma agrária assegurando a propriedade da terra a todos que desejassem cultivála de modo a cumprir a função social estabelecida pelo próprio Estatuto.

Com a relativa abertura política do Brasil em 1978, retoma-se o debate sobre a reforma agrária. Surgia a polaridade de opiniões, de um lado os trabalhadores rurais, os movimentos sociais e igreja do outro a Tradição, Família e Propriedade (TFP).

Em março de 1979, assume a Presidência da República o General João Batista Figueiredo, apontando em seu programa de governo prioridades à agricultura como resposta às instabilidades da década de setenta, marcada como o período onde houve um aumento do grau de concentração fundiária, seja de posse, seja da propriedade da terra. Em maio do mesmo ano, em Brasília, acontece o III Congresso Nacional de Trabalhadores Rurais, quando a Confederação Nacional dos Trabalhadores Rurais (CONTAG) levanta a bandeira da reforma agrária, não apenas como motivação política, mas também como execução da legislação vigente, mantendo a chama da luta dos trabalhado- res brasileiros contra o monopólio da terra.

Um marco importante na modificação do modelo de reforma agrária aconteceu em 1982, com surgimento dos Planos Estaduais de Terras Públicas e de Regularização Possessória, decorrente das eleições diretas para os governos estaduais, quando houve forte mobilização popular. Em 1986 surge o Programa de Reforma Agrária via desapropriação por interesse social com base no Estatuto da Terra.

O Governo Federal, no mandato do Presidente José Sarney, em 1986, como forma de resolver os problemas agrários, criou o I Programa Nacional de Reforma Agrária (PNRA), constituindo-se de um conjunto de políticas públicas visando beneficiar famílias rurais em todo o país.

No Governo de Collor de Melo, iniciado em 1992, foi criado o Programa Emergencial de Reforma Agrária. Itamar Franco, 1993, viabilizou o Programa, regulamentando a Lei Ordinária, vetando partes que poderiam viabilizar a execução do Programa conforme planejado, limitando-se, no geral, a uma administração marcada tão somente por grandes desapropriações.

Os anos de gestão do Presidente Fernando Henrique Cardoso, a partir de 1994, iniciaram vários programas voltados à questão da reforma agrária, dentre eles o Novo Mundo Rural, Banco da Terra, Projeto Casulo, Programa de Geração de Emprego e Renda Rural, Programa Nacional de Agricultura Familiar. Alguns desses programas permanecem no atual Governo do Presidente Luiz Inácio da Silva Lula.

Da trajetória conflituosa entre concentração de terras e reforma agrária no País resulta uma constatação pouco animadora frente às intervenções: os índices gerais de concentração não vêm sofrendo alterações que indiquem que o acesso por parte dos trabalhadores rurais tenha sido facilitado de forma global. Pelo contrário, parece ser unânime, na literatura especializada, a percepção de que a relação entre a população rural brasileira e o tipo de estrutura agrária do país consiste em uma acentuada concentração da propriedade fundiária. 


\subsection{Origem e classificação dos assentamentos}

O termo "assentamento", em nosso país, aparece inicialmente no âmbito da burocracia como política governamental, resultante de pressões exercidas pelos movimentos sociais frente às demandas por terra, referindo-se às diversas etapas da ação do Governo Federal, ordenando e reordenando os recursos fundiários em beneficio de trabalhadores rurais sem terra ou com pouca terra.

Os assentamentos remetem ao processo de fixação dos trabalhadores rurais à terra, com disponibilidade de condições adequadas para o uso do solo e o incentivo à organização comunitária. Esta estrutura, que resulta da intervenção do governo federal, pode ser definida como uma nova unidade de produção agrícola, em que os conteúdos produtivos e organizacionais são, em última instância, próprios das instituições onde foi formulada. As ações desencadeadas são definidas previamente e os critérios estabelecidos seguidos por ordem técnica objetivando a alocação de trabalhadores como forma de resolver problemas sócio-econômicos (Bergamasco e Norder, 2001).

O processo de implantação de assentamento no país avançou significativamente nas últimas décadas. Conforme se constata, o número de assentamentos cresceu $528,53 \%$ entre 1985 e 2001, ampliando em $353,60 \%$ as famílias beneficiárias. Predominam as intervenções no Nordeste, representando, em 2001, cerca de $45,32 \%$ do número de projetos de assentamentos. Neste contexto, no Piauí, entre 1985-2001 foram implantados 120 projetos beneficiando 7.347 famílias. Cabe ressaltar que do total de PA's, 108 foram implantados no período 19952001, beneficiando 6.251 famílias.

Os assentamentos resultam da ação do Governo Federal, segundo Bergamasco e Noder (2001), estas experiências podem ser classificadas em cinco tipos diferentes desde a sua implantação no Brasil, a partir de 1970: projetos de colonização ou colonização dirigida; reassentamento de populações atingidas por barragens de usinas hidrelétricas; Planos Estaduais de valorização de terras públicas e de regularização possessória; programa de reforma agrária, via desapropriação por interesse social e ocupação das reservas extrativistas para seringueiros da região amazônica.

\subsection{As dificuldades de gestão dos assenta- mentos}

No Brasil, em todas as experiências de assentamento, o Governo Federal foi e continua sendo até hoje o gestor, através do INCRA que é o responsável, como instituição federal, pela implantação dos PA's considerando todas etapas necessárias a sua sustentabilidade. O processo parte do Plano Nacional de Reforma Agrária (PNRA), que norteia todas as ações da Política de Reforma Agrária, que impõe, em qualquer que seja a forma de obtenção da terra, a obrigatoriedade de estudos de viabilidade econômica e dos recursos naturais do local, de modo a garantir que as famílias sejam assentadas em áreas que tenham condições de produzir e gerar renda a partir de seu trabalho.

Nos assentamentos de responsabilidade do INCRA, os procedimentos operacionais parecem indicar uma relação de total dependência dos assentados, e a gestão termina por ser implementada pelos técnicos do Instituto. Quando o PA é considerado emancipado, a gestão torna-se um grande problema. Para os assentados a posse da terra representa uma vitória da sobrevivência social, e para tal fim, precisam de orientações, através da capacitação contratada pelo INCRA, que propõe em sua metodologia elementos de caráter empresarial e competitivo. Os assentados, entretanto, possuem uma tradição cultural e são acostumados a executar ordens e tarefas, assim, na hora de administrar o lote como uma empresa, ocorre uma inversão de papéis, pois passam de empregados a dono, e terão que planejar, executar e controlar seus negócios.

Outra dificuldade está associada à gestão financeira. Os beneficiários ao chegarem aos assentamentos, ou mesmo aqueles que ali já se encontravam, não têm recursos financeiros e nem bens ventáveis para converter em recursos de investimento, pois suas atividades anteriores não eram suficientes para acumular capital. Poucos possuem uma experiência de relação de troca com os mercados locais e regionais. Portanto, não há condição para um trabalho que leve em conta 
a quantidade e a qualidade dos produtos, passando estes a servirem apenas para sobrevivência familiar.

Os assentados, no geral, não possuem conhecimentos suficientes para gerenciar o dinheiro, para investir; não sabem planejar e nunca assumiram compromissos contratuais com bancos; muitos são analfabetos ou analfabetos funcionais Tudo isso precisa ser considerado para análise da viabilidade dos PA's, seguindo o modelo estruturado pelo INCRA, que aponta a falta de uma postura empresarial como impedimento a produção com rentabilidade.

\section{Potencialidades econômicas, sociais e ambientais do assentamento Iracema}

Em março de 1917, a família de Mariano Mendes de Sousa inicia a história da comunidade São Pedro, situada no entorno da fazenda Iracema. Mariano foi seguido por muitas outras famílias que buscavam trabalho e melhores condições de vida na fazenda. Acreditavam haver maiores oportunidades pela existência de duas lagoas, Salgado e Bonita, limitantes ao rio Longá.

No dia 04 de outubro de 1999, a área foi considerada pelo INCRA como um imóvel com um número significativo de meeiros e estaria, portanto, cumprindo sua função social, sendo desapropriada e declarada de interesse social para fins de reforma agrária. Surgia assim, o Assentamento Iracema com titulação coletiva, área total de 2.251 ha e área média por família de 17,5 ha. O total de famílias assentadas foi de 104 .

Segundo o Plano de Desenvolvimento Sustentável (2001), o assentamento possui infra-estrutura básica oriunda da antiga Fazenda Iracema, o que inclui uma rede elétrica de alta tensão $(13,8 \mathrm{KV})$ e uma rede monofásica; um dique circulando a lagoa de 12.500 metros; 1.200 metros de linha de baixa tensão; um transformador de 112,5 kw e um outro de $45 \mathrm{kw}$; bolsão receptor de água; duas lajes de cimento para secagem de arroz; barracões para os trabalhadores; 10.500 metros de cerca de arame farpado; um trator completo e um motor com três bombas para irrigação.

Iracema conta ainda com uma estrada interna sem revestimento, com largura de 4 m e 1.755 Km de extensão. A casa da Fazenda possui cisterna com capacidade para 2,27 $\mathrm{m}^{3}$, curral, aprisco, reservatório de acumulação de água, estação de bombeamento e poço "cacimbão" com profundidade de 12 metros e diâmetro de 2 metros revestido com alvenaria.

Os tipos de solos encontrados, no geral, favorecem a agricultura e encontram-se em duas áreas, a alta e a baixa. Na área baixa há predominância de relevo plano a suavemente ondulado e não pedregoso, permitindo o uso de maquinas agrícolas. Contudo, esta área é próxima às lagoas, existindo um fator limitante à produção, que é o risco de inundação no período chuvoso. Mesmo assim, apresentam aptidão para a exploração de culturas de ciclo curto como hortaliças, melancia, melão, milho, feijão e arroz.

Encontram-se também na área baixa, solos salinos, planos e baixos que servem apenas para a pastagem de animais em busca de mineral natural. Esta faixa territorial não é extensa, e a vegetação é constituída por carnaúba, crioli, capim rasteiro e remela de macaco. Não possui nenhum potencial agrícola, ficando totalmente submersa no período chuvoso. Os solos que ficam às margens das lagoas são do tipo argilosos aluvionais, e contam com 400 hectares, dos quais 100 ha favorecem o cultivo de arroz e feijão.

$\mathrm{Na}$ área alta encontram-se as chapadas com dois tipos de solos, o argiloso-arenoso e a chapada densa de barro duro. Estes solos apresentam excelentes propriedades físicas para a agricultura, contudo apresentam limitações decorrentes da baixa fertilidade natural e acidez elevada que podem ser corrigidos com a incorporação de calcário e uso de fertilizantes (em padrões aceitáveis). Nos argilosos, a vegetação é composta por pereira, amburana, aroeira, relame, mentrasto, mocó, pau-d'arco e sabiá. Na chapada densa de barro duro, altos e planos, sua vegetação é composta de pau-pombo, folhadura, murici, pitanga, ata-brava, pau-terra, favela, pitomba-de-leite, jacarandá e tuturubá. Nos dois tipos de solos da área alta são cultivados feijão, milho e mandioca em roça de sequeiro, em pequena escala, em área de apenas 30 ha.

O Assentamento possui condições favoráveis para dinamizar a produtividade e 
cultivos existentes, bem como para implantar novas atividades produtivas. Exemplos são as lagoas que possuem potencial para turismo rural e para pesca do camarão de água doce e diversos peixes. Favorece estas possibilidades a existência de via de acesso fácil para escoamento da produção em relação mercados consumidores próximos como Parnaíba, Teresina, Fortaleza e São Luis.

\subsection{Educação, Saúde e Organização Social}

No Assentamento não existe unidade escolar, a estrutura educacional está localizada em uma comunidade próxima, São Pedro, que fica a $3 \mathrm{Km}$ da Agrovila dos assentados atendendo a 174 alunos com idade de 2 a 60 anos, segundo pesquisa do PDA (2001) e pertencente à rede municipal de educação de Buriti dos Lopes.

Dentre as famílias assentadas, 31 são beneficiadas do Programa Bolsa Escola em 2001, hoje denominado Bolsa Família, atendendo a 77 alunos, sendo no máximo 03 (três) cadastrados por família. O índice analfabetismo foi de 39,37\%, em 2001 um percentual abaixo dos padrões educacionais.

Iracema não possui posto de saúde, o mais próximo fica a $3 \mathrm{~km}$ da Agrovila dos assentados. O saneamento básico não existe, o lixo é jogado a céu aberto indiscriminadamente, amontoa-se nos quintais ou terreiros das casas favorecendo a contaminação dos animais e das pessoas, principalmente das crianças. A água consumida na Agrovila é fornecida através de um chafariz, sem nenhum controle de vigilância sanitária, favorecendo a contaminação no deslocamento e uso.

No Assentamento apenas 23 pessoas são associadas ao Sindicato dos Trabalhadores Rurais de Buriti dos Lopes. Este Sindicato passou muito tempo sem uma atuação efetiva na região, o que se credita um fraco poder de mobilização dos trabalhadores. A principal forma de organização é a Associação dos Trabalhadores da Fazenda Iracema - ATFI, fundada em março de 2000.

A Associação encontra-se regularizada e estruturada. Sua finalidade, de acordo com o Estatuto, é prestar serviço e representar juridicamente seus associados.

\subsection{Atividades Agropecuárias e Progra- mas e Créditos de Investimentos}

No Assentamento há apenas dois tipos de atividades econômicas, a pecuária e agricultura. A pecuária é de autoconsumo e atividade agrícola destina-se a subsistência. $\mathrm{O}$ plantio consiste em dois sistemas: vazante e roça.

Na vazante é cultivado arroz, feijão e milho. A produção de arroz representa, segundo os trabalhadores, a fonte de renda mais importante $\mathrm{O}$ cultivo de feijão apresenta um rendimento de $1.200 \mathrm{~kg} /$ ha e 36 toneladas por safra. A vazante concentra-se nas áreas que margeiam as lagoas, onde é proibida, por lei, esse tipo de atividade agrícola.

Para o cultivo em roça de sequeiro, os trabalhadores desmatam todo ano locais diferentes, fazendo em média 3 linhas (1/2 ha) por família. Cerca de $30 \%$ dos assentados cultivam nessas terras. Os produtos cultivados são feijão, milho e mandioca. No geral, a produção é baixa e tem como fator preponderante, segundo os assentados, a irregularidade das chuvas na região.

Os primeiros créditos que os assentados receberam foram de implantação, fomento e alimentação, para assegurar minimamente condições para a permanência das famílias no assentamento, e foram adquiridos um trator e três bombas para irrigação para o cultivo do arroz.

Os programas escolhidos como prioritários no PDS foram: o Programa de Capacitação, Preservação e Conservação do Meio Ambiente e o de Fortalecimento Institucional e Apoio ao Beneficiamento e Comercialização que ainda não foram executados. Nos demais, apenas alguns projetos foram implantados como, por exemplo, a construção de armazém e pedra de secagem (Programa Desenvolvimento da Agricultura e Pecuária); a construção da Agrovila, instalação de energia elétrica e um chafariz (Programa Cidadania e Desenvolvimento Social). Cabe ressaltar que os recursos destinados à execução dos projetos do Programa Cidadania e Desenvolvimento Social são oriundos de outras fontes financiadoras parceiras, comumente articuladas para o suporte ao Assentamento.

Muitas foram as dificuldades para execução dos projetos, como por exemplo a 
construção da Agrovila. Iniciada a construção das casas, as obras ficaram, por diversas vezes, paralisadas por falta de material (telhas, portas e acabamento externo) e abandono da construtora contratada pelo INCRA, após ter recebido duas parcelas do financiamento. Porém os problemas foram solucionados, liberando-se a terceira e última parcela dos recursos diretamente aos assentados que adquiriram o material necessário (especialmente cimento) e concluíram as residências, utilizando a própria mão-de-obra.

\section{Produção agrícola e meio ambiente no Assentamento Iracema}

A pesquisa tomou como referência os cadastros das famílias realizados pelo INCRA em 1999, à época da desapropriação. Assim, o nosso levantamento estatístico é composto por 104 famílias, de onde partimos para delimitar a amostra da pesquisa. Para tanto foram considerados que as famílias assentadas possuíam duas origens:

1. As que tinham domicílio na comunidade São Pedro, totalizando 92 famílias, cujos processos de assentamento foram homologados em 2000;

2. As que tinham domicílio dentro da área que foi desapropriada, sendo beneficiárias cinco famílias em 2001 e sete famílias em 2004.

Inicialmente foram aplicados questionários com as 12 famílias que foram assentadas em 2001 e 2004, e num segundo momento 28 famílias, das assentadas em 2000, totalizando 40 questionários aplicados aos chefes das famílias. O questionário era composto por três seções. A primeira reunia dados referentes à produção e à renda. A segunda sobre a comercialização da produção, e a terceira, dados sobre os efeitos das práticas agrícolas sobre o meio ambiente como condições de domicilio, saúde e educação.

O objetivo dos questionamentos era apreender o processo de implantação e desenvolvimento do PA considerando as relações entre as atividades agrícolas e uso dos recursos naturais. Sobre a produção agrícola, visava perceber a existência de aumento de produção, de área plantada e de produtividade. Com a dimensão renda, buscavase a regularidade e o destino dos créditos e como repercutiu nos nível de renda das famílias. Os questionamentos relativos à comercialização visavam saber se os assentados haviam mudado a forma de vender os seus produtos e se havia alguma inserção no mercado local. No que diz respeito ao Meio Ambiente, o objetivo foi analisar o uso adequado dos recursos naturais de acordo com a legislação (Lei 6938 - 31.08.81).

Foram utilizadas, ainda, entrevistas com roteiro semi-estruturado composto de quatro perguntas sobre o PA. Foram entrevistados o Presidente do Sindicato dos Trabalhadores Rurais de Buriti dos Lopes e o Presidente da Associação dos Trabalhadores da Fazenda Iracema buscando perceber as opiniões sobre a produção, renda, comercialização e uso dos recursos naturais no Assentamento. Entrevistaram-se, também, técnicos das instituições vinculadas ao processo de implantação do PA, do INCRA e IBAMA.

Com os técnicos do INCRA objetivavase obter informações sobre o processo de negociação da terra e laudo de vistoria. $\mathrm{O}$ Instituto forneceu, ainda, o mapa do Assentamento e da agrovila, cadastro dos assentados no processo de implantação do Projeto e Plano de Desenvolvimento Sustentável (PDS), bem como informações relativas a liberação dos créditos com seus respectivos valores. No IBAMA a entrevista foi realizada com o técnico responsável pela fiscalização e autuação na região do Assentamento.

\subsection{Caracterização das Atividades Agrícolas}

Assegurar condições para o desenvolvimento de produção e renda sem comprometer o meio ambiente constitui o principal desafio no Assentamento Iracema. A constatação resulta da pesquisa direta realizada no PA, segundo a qual esta preocupação encontra-se presente no cotidiano da comunidade, sendo reconhecida como legítima e necessária em função da natureza da área, embora, na prática, o manejo da terra pelos assentados indique dificuldades de concretização. As limitações sobre o processo parecem indicar o comprometimento de sustentabilidade, uma vez que com reduzida utilização de recursos financeiros, em cada safra, uma diminuição na produção. Para melhor caracterização tomamos, inicialmen- 
te, como referência a produção predominante, a agrícola.

O cultivo não está diretamente voltado ao mercado, portanto, apresenta-se, ainda, como eminentemente de subsistência. A agricultura corresponde a $98 \%$ da atividade econômica predominante entre os assentados, sendo pouco diversificada, limitandose ao plantio de arroz, feijão, milho e mandioca.

A área plantada, desde que foi implantado o Assentamento, corresponde praticamente ao cultivo de vazantes, às margens das lagoas, sendo esta área de preservação permanente onde é vedado, por lei, o exercício de atividades econômicas. Nas chamadas áreas altas, pratica-se a roça de sequeiro ou como os assentados denominam roça de toco. Nestas roças plantam-se, em 30 ha, feijão, milho e mandioca, sendo que cada família cultiva no máximo 3 linhas, o equivalente a $1 \backslash 2$ ha.

O cultivo baseia-se exclusivamente na mão-de-obra das famílias dos assentados com o emprego de tecnologias simples. $\mathrm{O}$ trabalho desenvolvido procura adaptar-se às condições apresentadas pelas áreas cultivadas. Nas vazantes, por exemplo, os trabalhadores costumam fazer o plantio e replantio de arroz utilizando as mãos, não sendo raro encontra-se assentados sem o polegar direito, em decorrência do desgaste provocado pelas muitas horas de atividades agrícolas manuais.

Considerando a dimensão renda, constata-se que no assentamento houve um incremento nos rendimentos familiares, embora estes não estejam diretamente relacionados à produção desenvolvida pelo fato da produção não ter aumentado de 2001 até 2004.

Em 2004, considerando o universo pesquisado para este trabalho, 40 famílias, constatou-se uma elevação significativa no nível de renda máximo auferido pelas famílias do Assentamento, passando de $\mathrm{R} \$ 320,00$ (trezentos e vinte reais) em 2001 para $\mathrm{R} \$ 520,00$ (quinhentos e vinte reais).

A elevação do nível de renda está associada a diversas variáveis: ao crédito de implantação do PA que corresponde a fomento e alimentação que foram entregues diretamente às famílias; aos créditos de ha- bitação e investimentos que permitiram a contratação de mão-de-obra das famílias para a construção da Agrovila, do armazém, da pedra de secagem de arroz e da barragem; ao Programa Bolsa Escola, aposentadorias e outros rendimentos, como por exemplo, o recebimento de doações de parentes, especialmente residentes no Centro-Sul.

\subsection{As repercussões sobre o meio ambiente}

O Assentamento Iracema possui oficialmente as áreas de reserva permanente e legal. A área de reserva permanente ${ }^{1}$ dista 50 metros do leito do rio Longá, e 100 metros ao redor das lagoas, constituindo terras de domínio federal. A vegetação encontrada é típica destes leitos, como cabeça-branca, canastro, capa-bode, alecrim, melancia-dapraia, rabo-de-macaco e jangada (SILVA, 1999).

A área de reserva legal ${ }^{2}$ é constituída por 450 hectares, localizados na área alta, no Morro da Má Hora. A região é rica em variedades de vegetação nativa: amburana, pau-d'arco, aroeira, pereira, frei-jorge, marmeleiro preto, marmeleiro branco, piquiá, mororo, catingueira, sabiá, ameixa, mirindiba, farinha seca, marfim, quebra bucho, amora, catanduva, folha dura, murici, ata brava, maria-preta, pau pombo, pau-terra, tuturubá, favela, jacarandá, pitomba de leite, canastro, rabo-de-macaco, calumbi, carnaúba, jiquiri, capim cortador, maliça, melancia-de-praia, jitirana, pipoca, crioli, mandacaru, cajuí, capa-bode e orelha-deonça (SILVA, 1999).

As famílias assentadas praticam, predominantemente, a agricultura na área de reserva permanente e utilizam agrotóxicos na produção de arroz, comprometendo as lagoas e o rio.

A questão dos agrotóxicos merece destaque por afetar diretamente todo o agroecosistema, provocando uma toxicidade aguda e crônica, havendo a contaminação de material e produtos de colheita, dos solos, da água, do ar, além da fauna, da flora e do homem. Outras práticas são desenvolvidas e tornam-se danosas ao meio ambiente, como a erosão provocada pela barragem construída a cada ano separando o rio das lagoas para permitir o plantio de arroz, e as 
queimadas, de costume secular e uso constante no meio rural. As queimadas são praticadas por quase totalidade das famílias (93\%)s para limpar as roças de sequeiro. Outro agravante ambiental foi o desmatamento indiscriminado para a construção das casas sem que houvesse a preservação das arvores de grande porte.

Os resultados dos danos causados a natureza já são percebidos no Assentamento, com a redução da produção apontada como decorrente do desgaste da área, indicando, se não houver mudanças na prática, uma previsão em nada animadora para colheitas futuras.

Os cuidados com o meio ambiente são comprometidos, também, pela ausência de condições mínimas de saneamento e destino de lixo. As casas foram construídas com banheiros internos, porém sem as fossas, Quanto ao destino do lixo, $82 \%$ das famílias indicam queimar e $10 \%$ apenas o depositam a céu aberto, na frente da casa ou no quintal.

Constata-se, portanto, que o Assentamento necessita de um acompanhamento para tornar-se sustentável econômica e ambientalmente.

\section{Considerações Finais}

Para assegurar condições dignas de vida, o Assentamento precisa ser sustentável do ponto de vista econômico e ambiental e, para que isso aconteça, implica, na prática, mudanças de comportamento no plano pessoal, e no cuidado do meio ambiente.

No Assentamento a produção agrícola destina-se basicamente à subsistência. Transformar essa situação significa dar condições mínimas e oferecer oportunidades concretas para que os assentados possam ter rentabilidade e competitividade para atingir objetivos concretos como a melhoria da qualidade dos produtos colhidos e reduzir ao mínimo os custos unitários de produção, com uma perspectiva multidimensional que envolva a esfera econômica e social, em que a elevação da renda deve estar intimamente ligada às condições de vida, e incluam além de uma estrutura domiciliar favorável, aspectos outros como acesso à educação e saúde.

Informação e capacitação devem vir antes de qualquer atividade produtiva. A sustentabilidade econômica para ter sucesso depende diretamente de conhecimento básico, ou até profundo, sobre determinada atividade, que envolva a esfera ecológica e política ao mesmo tempo com o aproveitamento dos vegetais, animais e outros recursos naturais existentes que dependem da consciência dos assentados, no sentido de preservar e conservar pastagens, recursos naturais existentes na reserva legal, dando um maior isolamento para os animais silvestres da região.

Esses conhecimentos só poderão ser aprimorados através de atividades de capacitação com a intervenção do Estado, ou seja, da articulação da Associação do Assentamento com o Sindicato de Trabalhadores Rurais de Buriti dos Lopes, o Município e as instituições envolvidas com processo de implantação do Assentamento. Esta integração é indispensável para transformar o PA em área que proporcione uma maior produção de alimentos (aumento na produção) consumidos, uma complementação da renda familiar através do aproveitamento dos recursos naturais, a aquisição de equipamentos agrícolas que garantam maior agilidade no preparo das áreas de plantio, equipamentos de beneficiamento, secagem e armazenamento dos produtos, visando um maior aproveitamento da área existente e conseqüentemente a melhoria da qualidade de vida.

Assim, certamente haverá um aumento significativo na produção que poderá ser destinada à comercialização, como também na diversidade dos produtos cultivados pelas famílias assentadas, gerando uma preocupação com a comercialização e com o beneficiamento, justificando-se, desta forma, um programa de apoio ao beneficiamento e comercialização organizada da produção e capacitação em gestão comercial, ou seja, capacitando os assentados para melhorar a comercialização, estabelecendo contatos com agentes de mercado, oferecendo produtos de melhor qualidade, buscando parcerias com o poder público e instituições diversas ou visitando outros assentamentos que desenvolvem experiências de comercialização de produtos agrícolas para atingir maior parcela do mercado local e de outros municípios.

Como se vê, pode-se introduzir estas mudanças no Assentamento com um pro- 
pósito de formar um novo cidadão. Não somente é necessário e possível como é especialmente urgente fazê-lo. Enquanto não se faça, as medidas convencionais que os governos adotam em prol do Assentamento, continuarão produzindo resultados muito modestos e desperdiçando em grande parte os escassos recursos oficiais e que são caros. Isto porque os assentados não estarão tecnicamente preparados para beneficiar-se deles, nem assumir com responsabilidade pelo seu próprio desenvolvimento.

A sustentabilidade ambiental do Assentamento depende da capacitação das famílias em técnicas agrícolas que preservem os recursos naturais, especialmente, no que diz respeito a não utilização da área de reserva permanente, que são as áreas das lagoas Salgado e Bonita.

\section{Notas}

${ }^{1}$ A Lei 6.938 - 31/08/81 determina as Áreas de Preservação Permanente como Reservas Ecológicas. São florestas e demais formas de vegetação natural situadas: ao longo dos rios ou de qualquer curso d'água desde o seu nível mais alto em faixa marginal com largura mínima de 30 a 600 metros, ao redor das lagoas, em regra, é vedado por lei o exercício de atividades econômicas, em virtude da especial importância da manutenção de sua cobertura vegetal, decorrente da fragilidade dos ecossistemas naturais e das formações geomorfológicas e paisagísticas em que se inserem (CARNEIRO, 2001. p.120).

${ }^{2}$ Pode ser compreendido, nos termos do art. 60 do código florestal, como a área de cada propriedade rural afetada necessariamente à preservação da cobertura vegetal natural, em faixas percentuais variáveis de acordo com a fisionomia ou a região do País, onde não e permitido o corte raso e nem a alteração do uso do solo ou a exploração com fins comerciais (CARNEIRO, 2001. p.122).

\section{Referências}

BERGAMASCO, Sônia M.; NORDER, Luis A. Cabello. O que são assentamentos rurais. São Paulo: Brasiliense, 2001.

CARNEIRO, N.I. Política florestal. Curitiba: FUPEF, 2001.

INCRA. Plano de Desenvolvimento Sustentavel do Assentamento Iracema Município de Buriti dos Lopes-PI, 2001.

SILVA, José Onofre. Laudo de avaliação imóvel Iracema Buriti dos Lopes. Teresina: Instituto Nacional de Reforma Agrária - INCRA, 1999. 